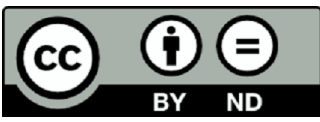

Mariola Jarczykowa

Uniwersytet Śląski

\title{
Nowe źródła do badań literackich i bibliologicznych dawnego piśmiennictwa Wielkiego Księstwa Litewskiego w świetle współczesnych metodologii
}

\begin{abstract}
Zarys treści
W artykule przedstawiono nowe źródła pozwalające rozszerzyć dotychczasowe badania nad dawnym piśmiennictwem Wielkiego Księstwa Litewskiego. Przywołane przykłady odzwierciedlają jednocześnie współczesne metodologie literackie i bibliologiczne. Bibliotekoznawcy wykorzystują metodę funkcjonalną i stosują dyrektywę badawczą „kultura książki” m.in. w odniesieniu do wileńskich środowisk klasztornych.

Geopoetyka i geokrytyka umożliwiają ujawnianie znaczenia przestrzeni, miejsc pamięci czy geograficznych nazw własnych. Zastosowanie tej metody wobec twórczości Daniela Naborowskiego czy diariusza Bogusława Kazimierza Maskiewicza pozwala na wydobycie z tych tekstów specyfiki podejścia do mniej lub bardziej znanych miejsc na mapie Rzeczypospolitej, zwłaszcza Wielkiego Księstwa Litewskiego. Metoda badań strukturalnych, stosowana zarówno przez literaturoznawców, jak i bibliologów, oparta na analizie ramy literacko-wydawniczej, została przedstawiona na przykładzie lwowskiego rękopisu zawierającego wiersze okolicznościowe poświęcone Radziwiłłom birżańskim oraz na podstawie nieznanego, unikatowego druku przekładu Niektórych psalmów Dawidowych Salomona Rysińskiego. Zwrócono także uwagę na znaczenie badań retorycznych, wskazując możliwość wykorzystania nieznanych mów świadczących o kulturze oratorskiej Wielkiego Księstwa Litewskiego.
\end{abstract}

Słowa klucze: geopoetyka, retoryka, kultura książki, literatura okolicznościowa, Radziwiłłowie Keywords: geopoetics, rhetoric, book culture, occasional lierature, the Radziwiłł family

Dziedzictwo piśmiennicze Wielkiego Księstwa Litewskiego budzi zainteresowanie badaczy różnych dziedzin - historyków, literaturoznawców, bibliologów, historyków sztuki. Wiele tekstów zostało już poddanych analizom pozwalającym wzbogacić wiedzę na temat spuścizny pisarzy związanych z tym terenem, wiele jednak ciekawych zabytków nadal czeka na opracowanie. Na zwiększenie możliwości badań w tym zakresie wpływ mają zarówno nowo odkryte źródła, 
jak i nowe metodologie pozwalające na wydobycie innych, nieznanych aspektów interpretowanych tekstów.

Przez wiele lat literaturoznawcy skupiali swoją uwagę na utworach z obiegu wysokoartystycznego oraz na znanych i uznanych twórcach. Socjologia literatury ukazała jednak znacznie większe możliwości rozszerzenia tej bazy źródłowej, wskazując na różne obiegi popularne oraz perspektywy badań tekstów okolicznościowych. Od kilkunastu lat prowadzi się w tym zakresie intensywną działalność wydawniczą oraz interpretacyjną. W 1993 r. z inicjatywy Janusza Pelca w Instytucie Literatury Polskiej Uniwersytetu Warszawskiego powstała Pracownia Literatury Okolicznościowej i Popularnej Renesansu i Baroku. Według założeń zespołu „Rezygnując z apriorycznego wartościowania, pracownia inicjuje badania wyjaśniające miejsce nurtów okolicznościowego i popularnego w dawnej kulturze, istotę form reprezentujących oba nurty, wpływ na literaturę wysoką itp."

W piśmiennictwie okolicznościowym dotyczącym magnaterii Wielkiego Księstwa Litewskiego można wskazać kilka nowych źródeł rękopiśmiennych odwołujących się do przedstawicieli takich rodów jak: Radziwiłłowie, Sapiehowie czy Dorohostajscy. Wśród zabytków skopiowanych w sylwach znajdują się także teksty okolicznościowe utrwalające radosne i smutne wydarzenia w rodzinach tych magnatów.

Cennym manuskryptem jest autograf Krzysztofa Monwida Dorohostajskiego, zachowany do dziś w zbiorach Biblioteki Zakładu Narodowego im. Ossolińskich (sygn. II 185). Rękopis, oprócz utworów łacińskich i greckich, zawiera także wiersze polskie Dorohostajskiego, świadczące o jego kulturze literackiej i umiejętnościach rymotwórczych. Autorstwo tych tekstów zostało bardzo wyraźnie zaznaczone: „Carmina compositionis meae, quaedam” [k. 4r $]^{2}$. Najobszerniejszym utworem jest Lament Rzeczypospolitej Matki po rozjachaniu z nierzadnej elekcyjej anno 1587. Okolicznościowe dzieło, zainspirowane wyborem polskiego władcy w czasie tzw. trzeciego bezkrólewia, pozwala nie tylko ocenić warsztat pisarski marszałka, ale także wyraźnie ukazuje jego sympatie polityczne. Dorohostajski był bardzo dobrze zorientowany w sytuacji, gdyż uczestniczył w rokowaniach $\mathrm{z}$ posłami cara Fiedora ${ }^{3}$. Lament przedstawia jednak okres, kiedy poparcie Litwinów zdecydowanie zmniejszyło się wobec moskiewskiego kandydata, o czym świadczą ostatnie wersy utworu, wyraźnie wskazujące Maksymiliana jako pożądanego następcę Stefana Batorego. W liście Monwida z 18 września 1587 r. znajduje się wzmianka o tym tekście dołączonym do „pisania” skierowanego do Krzysztofa Radziwiłła „Pioruna”: „Posyłam też W[aszej] M[iłości] Lament RP wierszem pisany, żeby się też W[asza] M[iłość] inter caetera (acz ci i bez tego

${ }^{1}$ Zob. http://ilp.uw.edu.pl/pracownia-literatury-popularnej-i-okolicznosciowej-renesansu-i-baroku/ [27.07.2015].

2 Zob. M. Jarczykowa, Krzysztofa Dorohostajskiego zabawy Muzom poświęcone, „Odrodzenie i Reformacja w Polsce" 2014, t. 58, s. 105-122.

${ }^{3}$ K. Lepszy, Dorohostajski Krzysztof Mikołaj, w: Polski Słownik Biograficzny, t. 5, Kraków 1939, s. 331. 
jest podobno czem inszem) miał czem zabawić"4. Zestawienie wierszowanego komentarza do „nierządnej elekcyjej” z ówczesną korespondencją Dorohostajskiego oraz z mową Krzysztofa Radziwiłła „Pioruna” skierowaną do Zygmunta III w 1587 r. ${ }^{5}$ pozwala lepiej zrozumieć stanowisko Wielkiego Księstwa Litewskiego wobec wyboru monarchy.

Spod pióra Dorohostajskiego wyszły także utwory reprezentujące facecjonistykę, lirykę miłosną i wiersze opiewające uroki przyrody (Wiosny opisanie). Rymowane teksty Monwida nie tylko wzbogacają dotychczasowy stan wiedzy o jego spuściźnie literackiej, ale kierują też uwagę badaczy literatury na artystyczne i intertekstualne warstwy najbardziej znanego utworu marszałka wielkiego litewskiego, czyli wydane kilkakrotnie dzieło Hippica, to jest o koniach ksiegi.

Innym cennym rękopisem jest zachowany we Lwowskiej Naukowej Bibliotece NAN Ukrainy we Lwowie manuskrypt ze zbiorów Baworowskich 1332/II (dawniej sygn. Baw.V.B.7. nr 1332), pochodzący z połowy XVII w. ${ }^{6}$ Według zapisków proweniencyjnych księga należała m.in. do Michała Kazimierza Pozarzyskiego, który skopiował wiele tekstów okolicznościowych i utworów literackich m.in. Kaspra Twardowskiego i Hieronima Morsztyna. Wśród wierszy znalazły się dzieła znane $\mathrm{z}$ innych przekazów oraz unikatowe, ciekawe teksty nieznane badaczom literatury, np. sielanki ${ }^{7} \mathrm{i}$ cały zespół utworów poświęconych Radziwiłłom birżańskim, napisanych z okazji narodzin nowych członków rodu (genetliakony), ich imienin czy śmierci.

Najobszerniejszy tekst w tym zespole to Lament na pogrzeb Księcia Pana Wojewody wileńskiego, hetmana Wielkiego Księstwa Litewskiego napisany przez Waleriana Gorzyckiego, pisarza natenczas pokojowe $[g]$. Pośmiertny wizerunek Krzysztofa Radziwiłła eksponował przede wszystkim zasługi mądrego senatora i hetmana, mężnego obrońcy ojczyzny, skutecznie dającego odpór wrogom - Moskalom i Szwedom. W dołączonych do lamentu wierszach wskazujących na korony, na które zasłużył birżański książę, zostały wyróżnione jego sukcesy militarne:

Kiedyś murom smoleńskim czasu oblężenia Dał odsiecz, a mieszczany z ciasnego więzienia Nieprzyjaciół wybawił $[\ldots]^{8}$.

\footnotetext{
${ }^{4}$ Archiwum Główne Akt Dawnych, Archiwum Radziwiłłów, dz. V, nr 3213/I.

${ }^{5}$ Zob. Mowa Książęcia Jmci Krzysztofa Radziwiłła do króla Jmci Zygmunta III in A[nn]o 1587, rkps Biblioteki XX Czartoryskich w Krakowie 439, s. 738-743.

${ }^{6}$ Za wskazanie mi tego rękopisu dziękuję dr hab. Marii Barłowskiej.

${ }^{7}$ D. Piotrowiak, Dwie anonimowe sielanki z pierwszej połowy XVII wieku z rękopisu Biblioteki Baworowskich we Lwowie, „Terminus” 2014, z. 4 (33), s. 495-536.

${ }^{8}$ Corona muralis ob Smolenscium obsidione liberatum, Biblioteka Naukowa NAN Ukrainy we Lwowie [dalej: LNNBU], sygn. 1332/II, s. 91.
} 
[...] Gdyś skuteczną sprawiwszy obronę,

Zatrwożoną Mitawę chciwym Szwedom prawie

Z garła wyrwał 9 .

Panegiryk podkreślał przede wszystkim zasługi Radziwiłła dla Wielkiego Księstwa Litewskiego:

Chramie Litwa, nie mając podpory,

Odważnych dził i męstwa utraciła wzory.

Nie ma kogo do rady wysłać, nie ma kto by

Stanął przy niej i wczesnej ozdoby,

Gdy potrzeba mógł dodać ${ }^{10}$.

Wśród zalet zmarłego została także wspomniana jego pobożność oraz zaangażowanie w obronę współwyznawców:

Płacz i ty zasmucony Kościele w tej dobie,

Że już w krajach litewskich nie stało w żywocie

Tego, co przy twym umrzeć był gotów kłopocie ${ }^{11}$.

Zarazem jednak Gorzycki przedstawił zmarłego hetmana i senatora w otoczeniu rodziny: opisywał wielki żal bratanka - księcia Bogusława, pocieszał wdowę i wyrażał nadzieję na kontynuację zasług wojennych przez syna Janusza.

Autor wskazany w tytule wiersza jako „pisarz natenczas pokojowy” nie był do tej pory uwzględniany w charakterystyce środowiska pisarskiego skupionego wokół Radziwiłłów birżańskich. Oprócz Lamentu jego nazwisko pojawia się także w rękopisie Biblioteki Kórnickiej, w tytule wiersza Do Jej M[iłoś]ci Paniej Elżbiety Cikowskiej, wdowy na znak afektu dobrego i przyjaźni nieodmiennej Walerian Gorzycki 1654 Anno $^{12}$. Nie wiadomo, czy twórca komplementu skierowanego do „młodej, nadobnej i majętnej wdowy” był także autorem innych utworów skopiowanych w rękopisie lwowskim. Wiersze te powstały w terminie zbliżonym do daty śmierci księcia Krzysztofa, gdyż odwoływały się do tego smutnego wydarzenia, choć dotyczyły radosnego świętowania na birżańskim dworze z okazji narodzin kolejnych potomków książęcego rodu. Triumf Rzeczypospolitej niebieskiej nad szczęśliwie narodzonem księciem Krzysztofem Radziwiłem, Janusza podkomorzego $W$ [ielkiego] Ks[ięstwa] L[itewskiego] synem, w Lubeczu u Niemnu odprawowany został poświęcony wnukowi - imiennikowi hetmana. Autor wyrażał nadzieje związane z tymi narodzinami, traktując je jako rekompensatę dla księcia Janusza po śmierci ojca:

\footnotetext{
${ }^{9}$ Corona Navalis ob Victorias in aquis partas, LNNBU, sygn. 1332/II, s. 92.

${ }^{10}$ Lament na pogrzeb Księcia Pana Wojewody wileńskiego..., LNNBU, sygn. 1332/II, s. 90.

${ }^{11}$ Ibidem, s. 86.

${ }^{12}$ Rkps Biblioteki Kórnickiej PAN, sygn. 1195, k. 449.
} 
O jakoż nie winszować książęciu takiemu,

Któremu Bóg w nagrodę jego świeżej straty

Daje synem cnót ojca wizerunk bogaty? ${ }^{13}$

Niestety, urodzony 20 marca 1642 r. Krzysztof niedługo cieszył swoich rodziców, gdyż zmarł w niemowlęctwie. Lat dorosłych doczekała natomiast jego o dwa lata starsza siostra - Anna Maria. Dla księżniczki także został napisany genetliakon pt. Kolumna radości nowo narodzonej księżnie Jej M[iło]ści Annie Mariej Radziwitównie, podkomorzance Wielkiego Księstwa Litewskiego wystawiona. W radosnym wierszu opiewającym narodziny księżniczki wzmiankowana jest jej najbliższa rodzina (rodzice, dziadkowie, siostra ojca), przypomniane zostało także niedawne zamążpójście Katarzyny za Jerzego Karola Hlebowicza, skoro autor tak zwracał się do Krzysztofa Radziwiłła:

A iżeś zacne książę, świeżo kwiat swój miły W dary oddał zięciowi, przetoć tyż zrodziły Niebieskie Nimfy teraz w pierwszego nagrodzie Drugi, podobny temu w synowym ogrodzie ${ }^{14}$.

Narodziny wnuków przedstawiano jako zapowiedź pomyślnego rozwoju rodu, zwłaszcza po śmierci Krzysztofa Radziwiłła. Autor tak bowiem pocieszał dotkniętą stratą męża wojewodzinę wileńską:

Nie każdy był w Koryncie, jako powiadają,

Ani każdemu nieba, to, co tobie dają.

Luboć krzywdę, cna Księżno, uczyniły znaczną,

Ale nie tak Fortuna twoja już niebaczną,

Bo z czym inszym do ciebie z drugiej strony leci,

Otoć Bóg dał oglądać twoich dziatek dzieci ${ }^{15}$.

Rękopis lwowski składający się z części zatytułowanych Księga pierwsza Promptuarium nazwana oraz Księgi wtóre kozackim sajdakiem nazwane ma wyrazistą kompozycję, podkreśloną przez staranne dobranie elementów wprowadzających i zamykających sylwę. Badania nad ramą literacką książek nie tylko drukowanych, ale także rękopiśmiennych od lat prowadzone są $\mathrm{w}$ zespole kierowanym przez Renardę Ocieczek z Uniwersytetu Śląskiego ${ }^{16}$. W tradycji literackiej i wydawniczej wykształciły się takie elementy delimitacyjne jak: tytulatura, motto, aprobata

${ }^{13}$ Triumf Rzeczypospolitej niebieskiej, LNNBU, sygn. 1332/II, s. 32.

${ }^{14}$ Kolumna radości [...] Annie Mariej Radziwiłównie, LNNBU, sygn. 1332/II, s. 83.

${ }^{15}$ Do Księżny Jej M[iło]ści paniej wojewodzinej, LNNBU, sygn. 1332/II, s. 28.

${ }^{16}$ Zob.: O literackiej ramie wydawniczej w ksiażkach dawnych, red. R. Ocieczek, Katowice 1990; Przedmowa w książce dawnej i współczesnej, red. R. Ocieczek, przy współudziale R. Ryby, Katowice 2002; Dedykacja w książce dawnej i wspótczesnej, red. R. Ocieczek, przy współudziale A. Sitkowej, Katowice 2006. 
cenzorska, list dedykacyjny, stemmat, przedmowa do czytelnika, wiersz zalecający dzieło, „rozmowa autora z książką", zamknięcie, adresy do zoila, wykaz błędów druku opatrzony nieraz komentarzem autora lub drukarza. Metoda analizy strukturalnej cząstek delimitacyjnych, stosowana także przez bibliologów ${ }^{17}$, pozwala nie tylko na pogłębioną interpretację utworów, ale umożliwia przybliżenie sytuacji ich lektury przez obserwowanie sposobów oddziaływania na opinię czytelniczą. $\mathrm{W}$ analizowanym manuskrypcie ze zbiorów Baworowskich twórca sylwy zwracał się do czytelników, nazywając ich gośćmi odwiedzającymi jego księgę, zastrzegał się także, że wiersze dobierał tak, aby nie zarzucano mu uszczypliwości i złośliwości: „Nie wszech stanów tykam ani na gniew robię” (s. [5]). Autorem tekstów zalecających był Michał Pozarzyski, który w enigmonimie naprowadził na swoje dane: „Imię moje sześć liter od ziemie przezwisko” (s. [6]). Pod wierszem Ofiara Apollinowi, otwierającym księgę Promptuarium, pojawiły się jednak inicjały J.G., które wskazują na innego niż Pozarzyski twórcę tej metapoetyckiej wypowiedzi:

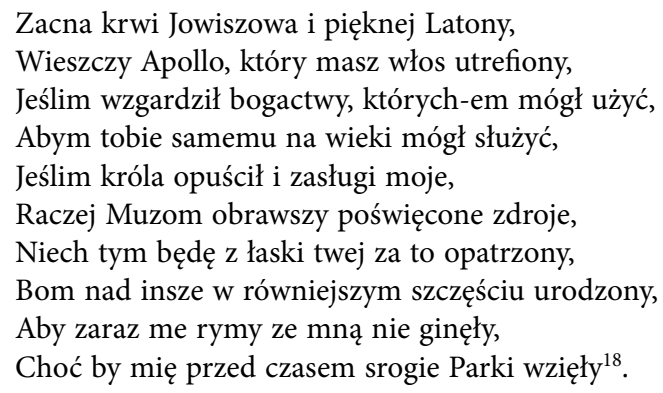

Na końcu księgi znajduje się podobna wypowiedź odautorska, utrzymana jednak nie w topice mitologicznej, a w duchu pobożności chrześcijańskiej. Najpierw bowiem twórca skierował do Boga modlitewną prośbę:

Panie rąk Twoich mdły ulepek z gliny,

Niech wiecznej śmierci nie popada winy ${ }^{19}$.

Następnie w rymowanej mowie skierowanej do śmierci tak zapowiadał trwałość pamięci o swoich dokonaniach:

Próżno się na mię grozisz ksieni niezdarzona,

Której kosie choć moja głowa nakłoniona,

Jednak się ja nie lękam, bom to zjednał sobie

I wdzięcznych łask, że choć me kości legą w grobie,

${ }^{17}$ Zob. A. Borysowska, Bibliologia a literaturoznawstwo - pokrewieństwo warsztatów historyka ksiązki i historyka literatury, w: Bibliologia. Problemy badawcze nauk humanistycznych, red. D. Kuźmina, Warszawa 2007, s. 93-94.

${ }^{18}$ Ofiara Apollinowi, LNNBU, sygn. 1332/II, s. [7].

${ }^{19}$ Confessio, LNNBU, sygn. 1332/II, s. 282. 
Przecie moje na wieki imię nie zaginie,

Które i dziś z mych rymów między ludźmi słynie ${ }^{20}$.

Nie wiadomo, jakie „rymy” wyszły spod pióra Pozarzyskiego, rzadko bowiem odnotowywał autorów przepisywanych tekstów, musiał jednak wyjątkowo cenić swoją twórczość, skoro w metapoetyckich wypowiedziach pobrzmiewają echa podobnych refleksji Jana Kochanowskiego ${ }^{21}$.

Rama literacko-wydawnicza poprzedzająca drugą część sylwy, zatytułowaną Kozacki sajdak, ma charakter makaroniczny, twórca wykorzystał tu polsko-łacińskie wiersze do czytelnika Stanisława Orzelskiego, który wprowadzał w ten sposób do lektury dzieła Macaronica Marfordi Mądzikovii Poetae Approbati ${ }^{22}$. Inna anonimowa wypowiedź do odbiorców poprzedzała odpis Lekcji Kupidynowych Kaspra Twardowskiego. Kopista uwzględniał więc w rękopisie także innych twórców delimitatorów, uznając te rymy za integralną część przepisywanych cykli.

Bardziej rozbudowane elementy okalające tekst występowały w drukach. Dzięki tym cząstkom można dziś określić związki łączące autorów i ich mecenasów oraz poznać pobudki napisania i wydania dzieła. Jeden z takich rzadkich druków stanowi unikat przekładu psalmów Salomona Rysińskiego ${ }^{23}$. Egzemplarze tej edycji były rzadkością już w XIX w., skoro Wincenty Korotyński stwierdzał: „[...] myśmy nie mieli sposobności oglądania tego białego kruka bibliograficznego [...]"24.

W dotychczasowych badaniach panowało przekonanie o niezachowaniu się opublikowanych egzemplarzy psałterza, odwoływano się więc do rękopiśmiennej, niepełnej kopii dzieła przechowywanej w Bibliotece Kórnickiej PAN. Okazuje się jednak, że w Książnicy Kopernikańskiej w Toruniu znajduje się unikat Niektórych psalmów Dawidowych (sygn. TN 23017), dzięki któremu można ocenić nie tylko wysiłki translacyjne Rysińskiego, ale także zbadać bogatą ramę literacko-wydawniczą dzieła. Oprócz wiersza na herb podpisanego przez Daniela Naborowskiego na czele książki pojawił się list dedykacyjny tłumacza psalmów, skierowany Do Oświeconego Książęcia na Birżach i Dubinkach Jego Mości Pana Krzysztofa Radziwiłła. W pierwszej części przypisania Rysiński nawiązał do herbu adresata, przedstawiając pochwałę rodu, by następnie przejść do charakterystyki księcia Krzysztofa, swego niedawnego ucznia i wychowanka. Dworzanin wskazywał na dobrą znajomość upodobań czytelniczych pana znajdującego przyjemność

${ }^{20}$ Mowa do śmierci od autora, LNNBU, sygn. 1332/II, s. 282.

${ }^{21}$ Por.: „Proszę niech ze mną za raz me rymy nie giną,/ Ale kiedy ja umrę, ony niechaj słyną!” J. Kochanowski, Ku Muzom, w: idem, Dzieła polskie, t. 1, oprac. J. Krzyżanowski, Warszawa 1976, s. 155.

${ }^{22}$ M. Pełczyński, Studia macaronica. Stanisław Orzelski na tle poezji makaronicznej w Polsce, Poznań 1960.

${ }^{23}$ Niektóre psalmy Dawidowe częścia poprawione, częścia znowu przełożone na stare noty od Solomona Rysińskiego za zleceniem starszych, druk Piotra Blastusa Kmity, Lubcz 1614.

${ }^{24}$ W. Korotyński, Salomon Rysiński. Studium, „Kurier Wileński” 1863, nr 132, s. 6. 
w studiowaniu prac historycznych, szczególnie tych opisujących zasługi jego antenatów. Przedstawił jednak swemu mecenasowi inną propozycję lekturową, czyli własną parafrazę psalmów.

Rysiński ofiarował swoją pracę translacyjną z dużymi obawami, miał świadomość trudności przekładu, zwłaszcza że przed nim dokonali tego inni wybitni, "gładcy" poeci. Podkreślał jednak, że odważył się opublikować swoją wersję psałterza na wyraźne zlecenie starszych. Było to również zaznaczone na karcie tytułowej oraz w przedmowie do czytelnika. Zwracając się do odbiorców, Pantherus wprost wyraził swoje obawy: „Rzeczesz, któż cię bił za szyję brać to na się? Prawda jest, że się podobno nieuważnie stało, iżem się o to kusił po tak wielu tłumaczach, którzy i bystrością dowcipu, i udatnością rymu daleko mię za sobą zostawili"25.

Oprócz dedykacji, przedmowy do czytelnika i stemmatu w druku pojawiły się pochwały Księgi Psalmów: w języku łacińskim Encomium psalmorum ex D[ivo] Basilio oraz po polsku Zalecenie psalmów Anonymi. Odnaleziony w Toruniu druk pozwala ocenić warsztat translatorski Rysińskiego oraz wskazać, które z jego psalmów znalazły się w zbiorowych tłumaczeniach „żołtarza”, np. w gdańskiej edycji Psalmów Dawidowych $z$ hymnami, gdzie na wstępie zaznaczono: „Psalmy, które $\mathrm{z}$ dawna były w kancjonale krakowskim ${ }^{26}$ (a jest ich tu w liczbie dwadzieścia i pięć), położyliśmy, tak jako są potrzebnie i szczęśliwie korygowane od ślachetnego Pana Salomona Rysińskiego, któremu z tej miary wielceśmy powinni”27.

Badania bibliologiczne dotyczące proweniencji i analizy typograficznej druku wzbogacą z pewnością analizy filologiczne, przybliżą swoiste cechy unikatu oraz ułatwią reedycję tej translacji psałterza.

Inny druk lubczańskiej oficyny Piotra Blastusa Kmity, niedawno odkryty i opisany przez Radosława Grześkowiaka, to drugie wydanie Przypowieści polskich Salomona Rysińskiego z roku 1621. Edycja została uzupełniona o blisko 290 paremii, z których większość nie była dotąd znana, a tym samym ani nie została uwzględniona w Nowej księdze przystów i wyrażeń przysłowiowych polskich, ani nie znajduje się w obiegu naukowym. Starodruk otwiera nieznany utwór Daniela Naborowskiego, będący przekładem epigramatu Erazma z Rotterdamu. Ramę wydawniczą wznowienia Rysiński dopełnił również wierszem Jana Zaborowskiego oraz cytatem z prywatnego listu Stanisława Serafina Jagodyńskiego ${ }^{28}$.

\footnotetext{
${ }^{25}$ S. Rysiński, Czytającemu, w: Niektóre psalmy Dawidowe..., k. iij.

${ }^{26}$ Feliks Bentkowski przypisuje Salomonowi Rysińskiemu autorstwo kalwińskiego kancjonału krakowskiego. Zob. Historia literatury polskiej, t. 1, Warszawa-Wilno 1814, s. 224.

${ }^{27}$ Psalmy Dawidowe $z$ hymnami..., druk Andrzeja Hünefelda, Gdańsk 1619.

${ }^{28}$ Zob. R. Grześkowiak, Przysłowia „sa jakoby szpikiem niejakim bystrego rozumu i głębokiego dowcipu ludzkiego". Nieznane wydanie Przypowieści polskich, od Solomona Rysińskiego zebranych, dwa tysiąca i dwieście z roku 1621, w: Sarmackie theatrum VII. W kręgu rodziny i prywatności, red. M. Jarczykowa, R. Ryba, Katowice 2015, s. 100-130.
} 
Nowe kategorie badawcze w bibliologii, na które zwrócił uwagę Krzysztof Migoń, to m.in. książka jako system informacyjny i jako dziedzictwo narodowe oraz światowe, wielojęzyczność w świecie książki, jej rola w kontaktach międzynarodowych ${ }^{29}$. Kategorie te są szczególnie przydatne w badaniu stosunków polsko-litewskich. Jako przykład można przywołać dwujęzyczny kancjonał litewski Kniga naboznistes krikśćioniszkos. Dzieło, wydane w oficynie Jerzego Rheta w Kiejdanach w 1653 r., było przypisane Januszowi Radziwiłłowi. Dedykację sygnowaną przez „starszych dozorców i pasterzy zborów W[ielkiego] Ks[ięstwa] Litew[skiego]" zredagowano w języku polskim, podobnie jak przedmowę do czytelnika, w której wyraźnie podkreślono wybór języka przekładu psalmów w kancjonale, wskazując na wybitnych tłumaczy polskich, niemieckich i francuskich, do których grona mieli też pretendować poeci kiejdańscy. Pomimo iż księga zawiera litewskie tłumaczenia psalmów, to jednak przed każdym $\mathrm{z}$ nich podano incipit $\mathrm{w}$ języku polskim. Kwestia, która wywołuje kontrowersje, to inicjatywa wyboru języka kancjonału. Wbrew opiniom wcześniejszych badaczy Henryk Wisner uważa, że tej decyzji nie można przypisać księciu Januszowi, gdyż jest to sprzeczne z dyrektywami Radziwiłła dotyczącymi nauki języków w szkole kiejdańskiej ${ }^{30}$. Wojewoda wileński sprawował natomiast osobisty nadzór nad kształtem typograficznym dzieła wydawanego w Kiejdanach, groził nawet drukarzowi, że jeżeli karta tytułowa nie zostanie ozdobiona odpowiednim miedziorytem „na serio tedy będzie w kłopocie"31. Kancjonał nadal budzi zainteresowanie badaczy litewskich i ponownie został wydany w Kiejdanach w 2001 r. $^{32}$

W najnowszych badaniach bibliologicznych coraz szerzej stosuje się termin „kultura książki”. Krzysztof Migoń tak przedstawił to zagadnienie: „Współczesne piśmiennictwo dotyczące zagadnień księgoznawczych, i to $\mathrm{z}$ obszaru samej bibliologii, i to $z$ kręgu innych nauk humanistycznych, pokazuje, jak korzystne w poznawaniu różnych obszarów i problemów jest stosowanie generalnej dyrektywy badawczej «kultura książki». W perspektywie teoretycznej idzie o teorię książki jako przedmiotu, narzędzia i funkcji w kulturze, w historycznej - o historię kultury książki różnych epok, w przestrzennej - o kulturę książki, państw, regionów, miast itd.; pytamy też o kulturę książki jednostek, grup wiekowych i zawodowych, różnych zbiorowości, całych społeczeństw i narodów; rozważamy przyszłość rozwoju kultury książki”33.

${ }^{29}$ Zob. K. Migoń, Bibliologia wśród innych nauk. Koncepcje, realizacje, perspektywy, w: Bibliologia. Problemy badawcze..., s. 23.

${ }^{30}$ H. Wisner, Janusz Radziwiłt 1612-1655, wojewoda wileński, hetman wielki litewski, Warszawa 2000, s. 227.

${ }^{31}$ Cyt. za: M. Stankiewicz, Bibliografia litewska od 1547 do 1701, Kraków 1889, s. 44.

${ }^{32}$ Knyga nobažnystès krikščioniškos (1653) - XVII a. Lietuvos kultūros paminklas: [straipsnių rinkinys] Kèdainiu krašto muziejus, Lietuvos reformacijos istorijos ir kultūros draugija, red. I. Lukšaitė i in., Kèdainiai 2001.

${ }^{33}$ K. Migoń, Bibliologia - nauka o kulturze książki, „Nauka” 2005, nr 2, s. 54-55. 
Jedno $\mathrm{z}$ zagadnień często podejmowanych $\mathrm{w}$ ostatnich latach stanowi kultura książki w środowiskach klasztornych dawnych epok, w tym zagadnienia związane $\mathrm{z}$ funkcjonowaniem piśmiennictwa zakonnego i bibliotek $\mathrm{w}$ aspekcie przestrzennym. W pracach bibliotekoznawców analizowane są pod tym kątem klasztory żeńskie ${ }^{34}$ i męskie ${ }^{35}$ m.in. na terenie Wielkiego Księstwa Litewskiego, szczególnie w Wilnie.

Metody stosowane w bibliologii w naturalny sposób łączą się z badaniami literaturoznawców. Najnowszymi teoretycznymi propozycjami z tego zakresu są geopoetyka i geokrytyka. Początki tej drugiej sięgają 2000 r., kiedy to ukazała się pierwsza książka zbiorowa wprowadzająca do obiegu koncepcje geokrytyczne: La Géocritique - mode demploi $i^{36}$. Metoda skupia się na wydobywaniu interakcji między przestrzeniami geograficznymi a ich reprezentacjami w literaturze i sztuce. Przestrzeń w perspektywie geokrytyki jest traktowana zarazem historycznie, jak i intertekstualnie. Uważa się bowiem, że kultura ma decydujące znaczenie dla rozumienia przestrzeni i miejsc ${ }^{37}$.

Geopoetyka doczekała się omówienia w wydanej ostatnio książce Elżbiety Rybickiej, która zwróciła uwagę na zwrot topograficzny w takich dyscyplinach badawczych jak: geografia kulturowa, antropologia miejsca i przestrzeni, geokulturologia i geohumanistyka ${ }^{38}$. Propozycje metodologiczne Rybickiej odnoszą się przede wszystkim do współczesnych tekstów, co jednak może zainspirować badaczy dawnego piśmiennictwa do wykorzystania zaproponowanych pojęć także w odniesieniu do źródeł staropolskich. Kategorie przestrzenne mogą być atrakcyjnymi narzędziami analitycznymi w badaniu relacji pomiędzy tożsamością narodową a literaturą, tak m.in. ujęła literaturę portugalską Ewa Łukaszyk: od średniowiecza do współczesności ${ }^{39}$.

${ }^{34}$ Zob.: J. Gwioździk, Kultura pisma i ksiażki w żeńskich klasztorach kontemplacyjnych dawnej Rzeczypospolitej XVI-XVIII wieku, Katowice 2015; eadem, Zakonne Wilno. Klasztory żeńskie. Teksty książki - biblioteki, „Acta Historica Universitatis Klaipedensis” 2007, t. 14: Baltijos Regiono istorija ir kultūra: Lietuva ir Lenkija. Socialine istorija, kultūrologija [History and culture of Baltic Region: Lithuania and Poland. Social history, cultural sciences], red. S. Pocyte, R. Sliužinskas, s. 195-207; J. Gwioździk, Female monasteries'space in the intellectual culture of the Grand Duchy of Lithuania, $\mathrm{w}$ : Lietuvos didžiosios kunigaikštystès moteru vienuolijos: Istorija ir dabartis skirta Kauno benediktiniu vienuolyno 390-čiui, red. A. Vasiliauskienè, Vilnius 2014, s. 175-184.

${ }^{35}$ I. Pietrzkiewicz, Zakonne Wilno. Klasztory męskie. Teksty - książki - biblioteki, „Acta Historica Universitatis Klaipedensis" 2007, t. 14, s. 185-193.

${ }^{36}$ E. Rybicka, Geopoetyka, geokrytyka, geokulturologia. Analiza porównawcza pojęć, „Białostockie Studia Literaturoznawcze" 2011, t. 2, s. 33.

${ }^{37}$ Eadem, Geopoetyka. Przestrzeń i miejsce we współczesnych teoriach i praktykach literackich, Kraków 2014, s. 78.

${ }^{38}$ Ibidem, s. 32.

39 „Narodowa geografia mityczna jest interpretowana jako narzędzie służące do utwierdzania poczucia tożsamości w zawiązku z danym terytorium”. Ibidem, s. 35. 
Łącząc przestrzenność z temporalnością, wyodrębnia się miejsca pamięci (lieux de mémoire). Można w odniesieniu do nich rozpatrywać m.in. geograficzne nazwy własne jako tropy toponomastyczne ${ }^{40}$. Symbolizują one idee narodowe, religijne, społeczne, odzwierciedlają systemy wartości i mentalności ${ }^{41}$. Tropy toponomastyczne wykorzystywane są przez pisarzy i poetów w dyskursie pamięciowym - przykładowo Daniel Naborowski w wierszu In Werki solatium utrwalił jeden z napisów zdobiących nieistniejący dziś dwór biskupa Eustachego Wołłowicza ${ }^{42}$, zaś we fraszce Droga $z$ Litwy do Prus żartobliwie wyzyskał dawne nazwy wsi, miasteczek i rzek ${ }^{43}$.

Jednym z najbardziej znaczących miejsc pamięci są Dubinki, gdzie rezydowała m.in. Barbara Radziwiłłówna oraz gdzie znajdowała się nekropolia jej krewnych $\mathrm{z}$ birżańskiej linii rodu. ${ }^{44}$

Interesującą kwestię stanowią metaforyczno-symboliczne określenia konkretnych miejsc, np. nazywanie Wilna Florencją lub Mediolanem Północy, Jerozolimą Litewską itd. Bardziej rozbudowane porównanie stolicy Wielkiego Księstwa Litewskiego do Rzymu przeprowadził Stanisław Rakowski, kanonik płocki i sekretarz Władysława IV, w liście do Andrzeja Trzebickiego, zestawiając warunki naturalne (położenie, rzeki, ukształtowanie terenu), jak i zabudowę miast nad Wilią i Tybrem ${ }^{45}$.

Badacze dostrzegają także związek między określonymi gatunkami mowy a miejscem ich wypowiadania (dwór - oda, cmentarz - epitafia, lamenty), poszukują takich gatunków, które najlepiej oddają specyfikę danego miejsca ${ }^{46}$. Geopoetyka skupia się na geograficznych wymiarach tekstu literackiego (geopoetyka grup i szkół literackich $)^{47}$ oraz na relacjach między autobiografią, biografią i przestrzenią. Krzysztof Mrowcewicz, idąc śladami wiersza $\mathrm{Na}$ oczy królewny angielskiej... Daniela Naborowskiego, przedstawia czytelnikom ciekawe miejsca XVII-wiecznej Europy, z których poeta czerpał inspirację do swojej twórczości. Przestrzeń geograficzna nie jest $\mathrm{w}$ tych ujęciach tylko scenerią, ale aktywnym obszarem doświadczeń biograficznych ${ }^{48}$. Analiza geobiograficzna uwzględnia także wewnętrzne przemiany osobowości. Można to zaobserwować np. w odniesieniu

\footnotetext{
${ }^{40}$ Ibidem, s. 96.

${ }^{41}$ Ibidem, s. 191.

42 Zob. M. Janicki, Willa Eustachego Wołłowicza $w$ Werkach pod Wilnem i jej epigraficzny program ideowy, „Barok” 1998, nr 2 (8), s. 139-149.

${ }^{43}$ Zob. D. Naborowski, Poezje, oprac. J. Dürr-Durski, Warszawa 1960, s. 50-51, 162.

${ }^{44}$ Zob. D. Karvelis, R. Ragauskienè, Iš Radvilu giminès istorijos: Dubingiu kunigaikštystè 1547-1808 m. Moksline monografija, Vilnius 2009.

${ }^{45}$ Zob. M. Barłowska, Wilno jako Rzym, czyli nieznany list Stanisława Rakowskiego do Andrzeja Trzebickiego, „Terminus” 2009, z. 1-2, s. 321-335.

${ }^{46}$ Zob. E. Rybicka, Geopoetyka. Przestrzeń i miejsce..., s. 74.

${ }^{47}$ Ibidem, s. 91.

${ }^{48}$ Zob. K. Mrowcewicz, Małe folio (historia jednego wiersza), Warszawa 2011.
} 
do tekstów Naborowskiego z okresu jego służby dworskiej i z okresu kiernowskiego. Ważne jest również dostrzeganie sprawczej, aktywnej roli przestrzeni dla praktyk memoratywnych, wobec obiektów materialnych i symbolicznych znaczeń (pomniki, cmentarze, tablice itd.) ${ }^{49}$. W tym zakresie cenne są inicjatywy polskich i litewskich filologów klasycznych, którzy podjęli się edycji inskrypcji z kościołów wileńskich ${ }^{50}$.

W kategoriach geopoetyki można ujmować także opisy dróg, np. wiodących z Wielkiego Księstwa Litewskiego do Korony. Taką trasę dokładnie przedstawia Bogusław Kazimierz Maskiewicz w Diariuszu drogi mojej na koronacyja Jana III, króla polskiego w R[ok]u Pańskim $1676^{51}$. Tytuł niepublikowanej dotąd relacji skopiowanej w XVIII-wiecznym rękopisie, przechowywanym obecnie w prywatnej bibliotece Kochlewskich ${ }^{52}$, eksponuje podróżny charakter relacji, chociaż opisy trasy z rodzinnego Serwecza do dawnej stolicy Polski oraz drogi powrotnej zajmują tylko początkowe i końcowe fragmenty dziennika. Diariusz, dzięki precyzyjnemu wskazaniu trasy podróży do podwawelskiego grodu, pozwala przybliżyć wiele szczegółów dotyczących ówczesnego podróżowania: Litwin często pisze o liczbie pokonanych $\mathrm{w}$ danym dniu mil, przedstawia miejsca i gospodarzy noclegów, kłopoty z zakwaterowaniem się w przeludnionym w czasie koronacji Krakowie. Dawną stolicę Polski zna dobrze, posługuje się konkretnymi nazwami ulic oraz dokładnie lokalizuje „przystanki” triumfalnego wjazdu Jana III Sobieskiego. Nie zatrzymuje się przy tym na opisach tych miejsc, jego uwagę przyciąga natomiast architektura okazjonalna, epitafium na katafalku przygotowanym na pogrzeb Jana Kazimierza i Michała Korybuta Wiśniowieckiego ${ }^{53}$.

Porównanie relacji Maskiewicza z opisem Krakowa w czasie intronizacji Sobieskich Gasparda de Tende’a wskazuje na inne spojrzenie na tę samą przestrzeń. Francuz w dziele Relation historique de la Pologne (Relacja historyczna o Polsce) przyznał, że uroczysty wjazd króla do dawnej stolicy Polski, pogrzeb dwóch jego poprzedników oraz sama koronacja miały imponującą oprawę: „i nie wiem, czy

${ }^{49}$ E. Rybicka, Geopoetyka. Przestrzeń i miejsce..., s. 307-308.

${ }^{50}$ Inscriptiones ecclesiarum Vilnensium - Inskrypcje z wileńskich kościołów - Vilniaus bažnyčiu ịrašai, t. 1, red. W. Appel, E. Ulčinaitè, Vilnius 2005.

${ }^{51}$ Kopiariusz z XVIII w. w prywatnych zbiorach Kochlewskich, k. 273r-280v. Panu Wojciechowi Kochlewskiemu dziękuję za udostępnienie mi elektronicznej wersji rękopisu.

${ }^{52}$ Zob. B.K. Maskiewicz, Electionis Series króla polskiego po abdykacji Jana Kazimierza Jagiełty w okopie między Warszawa a Wola odprawowana w roku 1669, wstęp i oprac. M. Makowski, Warszawa 1987.

${ }^{53}$ Autorem skopiowanego napisu opartego na wykazaniu przeciwieństw zmarłych królów był Jan Andrzej Morsztyn, na co wskazuje tytuł w rękopisie Biblioteki Ossolineum: Epithaphium Krolom Ichmościom Janowi Kazimierzowi i Michałowi pierwszemu napisane od JM Pana Morsztyna podskarbiego wielkiego koronnego i położone d. 30 Ianuarii na żałosnym katafalku w Krakowie wraz obom chowającym się. Anno 1676. Zob. J.A. Morsztyn, Utwory zebrane, oprac. L. Kukulski, Warszawa 1971, s. 342. 
widziałem kiedyś coś wspanialszego"54. Jednocześnie, opisując zabudowę Wawelu, porównał kompleks zamkowy do dziedzińca stróżówki pałacu paryskiego i stwierdził z rozczarowaniem, że nie ma w otoczeniu krakowskiej rezydencji ogrodu ani parku $^{55}$. Zbadanie percepcji przestrzennych w ujęciu Sarmaty i Francuza pozwala na ujawnienie specyficznego podejścia do mniej lub bardziej znanych miejsc na mapie Rzeczypospolitej.

W innej, skopiowanej w rękopisie ze zbiorów Kochlewskich relacji zatytułowanej Electionis Series króla polskiego po abdykacji Jana Kazimierza Jagiełty w okopie między Warszawa a Wola odprawowana w roku 1669 Maskiewicz opisał z kolei Warszawę, podając lokalizację gospód, w których się zatrzymywał i przedstawiając pożar miasta 9 czerwca 1669 r. Dzięki tej relacji można oszacować straty na ulicach Piwnej, Piekarskiej i św. Jana ${ }^{56}$.

O konieczności powiązania badań z konkretnym czasem i przestrzenią pisał Jakub Niedźwiedź ${ }^{57}$. Analizował on funkcjonowanie w stolicy Wielkiego Księstwa Litewskiego różnorodnych tekstów ujętych według podziałów klasycznej retoryki, $\mathrm{z}$ uwzględnieniem także funkcji religijnej przekazów piśmienniczych ${ }^{58}$.

Badania nad dawną wymową zajmują w dzisiejszym piśmiennictwie naukowym ważną rolę: Eugenija Ulčinaitè na podstawie 98 łacińskich rękopiśmiennych traktatów powstałych w szkołach jezuickich w Polsce i na Litwie zrekonstruowała XVII-wieczny schemat retoryczny ${ }^{59}$, Maria Barłowska przeanalizowała zbiory oratorskie z XVII i XVIII w. ${ }^{60}$, Małgorzata Trębska szczegółowo zajęła się mowami weselnymi ${ }^{61}$, Roman Krzywy zastosował retoryczną perspektywę interpretacji poezji staropolskiej, m.in. wierszy Daniela Naborowskiego ${ }^{62}$. Oprócz teoretycznego podejścia do wymowy duże znaczenie mają edycje oracji, które przybliżają sarmacką obyczajowość i kulturę słowa oraz są cennymi źródłami biograficznymi.

Wiele rękopisów ukrywa nieznane do tej pory materiały wymagające nie tylko ustalenia autorstwa, ale także okoliczności wygłoszenia mów. Badania te jednak

${ }^{54}$ G. de Tende, Relacja historyczna o Polsce, przeł. i red. T. Falkowski, wprowadzenie M. Forycki, Wilanów 2013, s. 204.

${ }^{55}$ Por. B. Manyś, Recepcja obrzędowości dworu polskiego w świetle „Relacji historycznej o Polsce” Gasparda de Tende'a, „Sensus Historiae” 2014, t. 16, nr 3, s. 40-41.

${ }^{56}$ M. Makowski, [Wstęp], w: B.K. Maskiewicz, op. cit., s. 5-11.

${ }^{57}$ J. Niedźwiedź, Kultura literacka Wilna (1323-1655). Retoryczna organizacja miasta, Kraków 2012, s. 8 .

${ }^{58}$ Ibidem, s. 11-12.

${ }^{59}$ E. Ulčinaitè, Teoria retoryczna w Polsce i na Litwie w XVII wieku. Próba rekonstrukcji schematu retorycznego, Wrocław 1984.

${ }^{60}$ M. Barłowska, Swada i milczenie, Zbiory oratorskie XVII-XVIII wieku - prolegomena filologiczne, Katowice 2010.

${ }^{61}$ M. Trębska, Staropolskie szlacheckie oracje weselne. Genologia, obrzęd, źródła, Warszawa 2008.

${ }^{62}$ R. Krzywy, Poezja staropolska wobec genologii retorycznej. Wprowadzenie do problematyki, Warszawa 2014. 
znacznie wzbogacają wiedzę o kulturze literackiej Wielkiego Księstwa Litewskiego oraz o znanych mówcach. Można wśród nich przykładowo wymienić przedstawicieli rodu Radziwiłłów - Albrychta Stanisława, Michała Kazimierza, Krzysztofa oraz jego dworzan ${ }^{63}$, a także Bogusława Kazimierza Maskiewicza czy Krzysztofa Stanisława Zawiszę ${ }^{64}$.

Interpretacje dawnego piśmiennictwa Wielkiego Księstwa Litewskiego z uwzględnieniem metod socjologii literatury, geopoetyki, retoryki mogą uzupełnić oraz wzbogacić inne badania literaturoznawcze i bibliologiczne, np. analizy cząstek ramowych czy tekstów okolicznościowych. Rozszerzenie bazy materiałowej o nieznane źródła rękopiśmienne i unikatowe druki (m.in. poprzez coraz szerszy dostęp do bibliotek cyfrowych) pozwoli natomiast na dostarczenie interesujących, nowych materiałów do różnorodnych prac interdyscyplinarnych.

\section{The new sources to literary and bibliological researches on the old literature of the Grand Duchy of Lithuania in the light of contemporary methodologies Summary}

The article presents the new sources which allow to broaden the existing research on the old literature of the Grand Duchy of Lithuania. The cited examples reflect contemporary literary and bibliological methodologies. Bibliologists use a functional method and apply a research directive called the "book culture" to (among others) the Vilnius monastic communities.

Geopoetics and geocriticism reveal the significance of the space, places of remembrance or geographic names. Applying this method to the work of Daniel Naborowski or Boguslaw Kazimierz Maskiewicz's diary enables to show the specifics of these author's approach to some more or less known places on a map of the Kingdom of Poland and especially the Grand Duchy of Lithuania. Structuralist method, used both by the literary critics and bibliologists, based on the analysis of literary-publishing frame was presented through two examples: the Lviv manuscript containing occasional poems dedicated to the Birże Radziwiłł family and the previously unknown, unique print of the translation of some David's psalms by Salomon Rysiński. In the article it has been also highlighted the importance of rhetorical research and indicated the possibility of using unknown orations which show the oratory culture of the Grand Duchy of Lithuania.

${ }^{63}$ Zob.: M. Jarczykowa, Przy pogrzebach rzeczy i rytmy. Funeralia Radziwiłłowskie $z$ XVII wieku, Katowice 2012, s. 175-251; eadem, Kultura oratorska w kręgu Radziwiłłów birżańskich. Nieznane mowy Piotra Kochlewskiego i Salomona Rysińskiego, „Odrodzenie i Reformacja w Polsce” 2012, t. 56, s. 115-135.

${ }^{64}$ Zob. M. Barłowska, Swada i milczenie..., s. 25-26, 58-62. 


\title{
Bibliografia
}

\section{Źródła rękopiśmienne}

\author{
Archiwum Główne Akt Dawnych \\ Archiwum Radziwiłłów \\ dz. V, nr 3213/I
}

Biblioteka Kochlewskich w Komorowie (zbiory prywatne)

Biblioteka Kórnicka PAN

sygn. 1195

Biblioteka Naukowa NAN Ukrainy we Lwowie

sygn. 1332/II

Biblioteka XX Czartoryskich w Krakowie

sygn. 439

Biblioteka Zakładu Narodowego im. Ossolińskich

sygn. II 185

\section{Źródła drukowane}

Inscriptiones ecclesiarum Vilnensium - Inskrypcje $z$ wileńskich kościołów - Vilniaus bažnyčiu ịrašai, t. 1, red. W. Appel, E. Ulčinaite, Vilnius 2005.

Kniga naboznistes krikścioniszkos, druk Jerzego Rheta, Kiejdany 1653.

Kochanowski J., Ku Muzom, w: idem, Dzieła polskie, t. 1, oprac. J. Krzyżanowski, Warszawa 1976.

Maskiewicz B.K., Electionis Series króla polskiego po abdykacji Jana Kazimierza Jagiełty w okopie między Warszawa a Wola odprawowana $w$ roku 1669, wstęp i oprac. M. Makowski, Warszawa 1987.

Morsztyn J.A., Utwory zebrane, oprac. L. Kukulski, Warszawa 1971.

Naborowski D., Poezje, oprac. J. Dürr-Durski, Warszawa 1960.

Niektóre psalmy Dawidowe cześcia poprawione, czesścia znowu przełożone na stare noty od Solomona Rysińskiego za zleceniem starszych, druk Piotra Blastusa Kmity, Lubcz 1614.

Piotrowiak D., Dwie anonimowe sielanki z pierwszej połowy XVII wieku z rękopisu Biblioteki Baworowskich we Lwowie, „Terminus” 2014, z. 4 (33), s. 495-536.

Psalmy Dawidowe z hymnami..., druk Andrzeja Hünefelda, Gdańsk 1619.

Tende de G., Relacja historyczna o Polsce, przeł. i red. T. Falkowski, wprowadzenie M. Forycki, Wilanów 2013.

\section{Opracowania}

Barłowska M., Swada i milczenie. Zbiory oratorskie XVII-XVIII wieku - prolegomena filologiczne, Katowice 2010.

Barłowska M., Wilno jako Rzym, czyli nieznany list Stanisława Rakowskiego do Andrzeja Trzebickiego, „Terminus” 2009, z. 1-2.

Bentkowski F., Historia literatury polskiej, t. 1, Warszawa-Wilno 1814. 
Borysowska A., Bibliologia a literaturoznawstwo - pokrewieństwo warsztatów historyka książki $i$ historyka literatury, w: Bibliologia. Problemy badawcze nauk humanistycznych, red. D. Kuźmina, Warszawa 2007, s. 85-98.

Dedykacja w książce dawnej i współczesnej, red. R. Ocieczek, przy współudziale A. Sitkowej, Katowice 2006.

Grześkowiak R., Przysłowia „sa jakoby szpikiem niejakim bystrego rozumu i głębokiego dowcipu ludzkiego". Nieznane wydanie Przypowieści polskich, od Solomona Rysińskiego zebranych, dwa tysiąca $i$ dwieście z roku 1621, w: Sarmackie theatrum VII. W kręgu rodziny i prywatności, red. M. Jarczykowa, R. Ryba, Katowice 2015, s. 100-130.

Gwioździk J., Female monasteries' space in the intellectual culture of the Grand Duchy of Lithuania, w: Lietuvos didžiosios kunigaikštystés moterų vienuolijos: Istorija ir dabartis skirta Kauno benediktiniu vienuolyno 390-čiui, red. A. Vasiliauskienè, Vilnius 2014, s. 175-184.

Gwioździk J., Kultura pisma i książki w żeńskich klasztorach kontemplacyjnych dawnej Rzeczypospolitej XVI-XVIII wieku, Katowice 2015.

Gwioździk J., Zakonne Wilno. Klasztory żeńskie. Teksty - ksią̇̇ki - biblioteki, „Acta Historica Universitatis Klaipedensis" 2007, t. 14: Baltijos Regiono istorija ir kultūra: Lietuva ir Lenkija. Socialine istorija, kultūrologija [History and culture of Baltic Region: Lithuania and Poland. Social history, cultural sciences], red. S. Pocyte, R. Sliužinskas.

Janicki M., Willa Eustachego Wołłowicza w Werkach pod Wilnem i jej epigraficzny program ideowy, „Barok” 1998, nr 2 (8), s. 139-149.

Jarczykowa M., Krzysztofa Dorohostajskiego zabawy Muzom poświęcone, „Odrodzenie i Reformacja w Polsce" 2014, t. 58.

Karvelis D., Ragauskienè R., Iš Radvilu giminès istorijos: Dubingiu kunigaikštystè 1547-1808 m. Mokslinè monografija, Vilnius 2009.

Korotyński W., Salomon Rysiński. Studium, „Kurier Wileński” 1863, nr 132.

Krzywy R., Poezja staropolska wobec genologii retorycznej. Wprowadzenie do problematyki, Warszawa 2014.

Lepszy K., Dorohostajski Krzysztof Mikołaj, w: Polski Słownik Biograficzny, t. 5, Kraków 1939.

Manyś B., Recepcja obrzędowości dworu polskiego w świetle „Relacji historycznej o Polsce” Gasparda de Tende'a, „Sensus Historiae” 2014, t. 16, nr 3.

Migoń K., Bibliologia - nauka o kulturze książki, „Nauka” 2005, nr 2.

Migoń K., Bibliologia wśród innych nauk. Koncepcje, realizacje, perspektywy, w: Bibliologia. Problemy badawcze nauk humanistycznych, red. D. Kuźmina, Warszawa 2007.

Mrowcewicz K., Małe folio (historia jednego wiersza), Warszawa 2011.

Niedźwiedź J., Kultura literacka Wilna (1323-1655). Retoryczna organizacja miasta, Kraków 2012.

O literackiej ramie wydawniczej w książkach dawnych, red. R. Ocieczek. Katowice 1990.

Pełczyński M., Studia macaronica. Stanisław Orzelski na tle poezji makaronicznej w Polsce, Poznań 1960.

Pietrzkiewicz I., Zakonne Wilno. Klasztory męskie. Teksty - książki - biblioteki, „Acta Historica Universitatis Klaipedensis" 2007, t. 14: Baltijos Regiono istorija ir kultūra: Lietuva ir Lenkija. Socialine istorija, kultūrologija [History and culture of Baltic Region: Lithuania and Poland. Social history, cultural sciences], red. S. Pocytè, R. Sliužinskas.

Przedmowa w książce dawnej $i$ współczesnej, red. R. Ocieczek, przy współudziale R. Ryby, Katowice 2002.

Rybicka E., Geopoetyka, geokrytyka, geokulturologia. Analiza porównawcza pojęć, „Białostockie Studia Literaturoznawcze" 2011, t. 2.

Rybicka E., Geopoetyka. Przestrzeń i miejsce we współczesnych teoriach i praktykach literackich, Kraków 2014.

Stankiewicz M., Bibliografia litewska od 1547 do 1701, Kraków 1889. 
Trębska M., Staropolskie szlacheckie oracje weselne. Genologia, obrzęd, źródła, Warszawa 2008.

Ulčinaite E., Teoria retoryczna $w$ Polsce $i$ na Litwie w XVII wieku. Próba rekonstrukcji schematu retorycznego, Wrocław 1984.

Wisner H., Janusz Radziwiłł 1612-1655, wojewoda wileński, hetman wielki litewski, Warszawa 2000.

Mariola Jarczykowa - prof. dr hab., kierownik Zakładu Historii Literatury Baroku i Dawnej Książki w Instytucie Nauk o Literaturze Polskiej im. Ireneusza Opackiego Uniwersytetu Śląskiego. Zainteresowania naukowe koncentrują się wokół problematyki staropolskiej kultury literackiej, ze szczególnym uwzględnieniem środowiska Radziwiłłów birżańskich. Autorka monografii: Książka i literatura w kręgu Radziwiłłów birżańskich w pierwszej połowie XVII wieku, Kultura epistolarna w kręgu Radziwiłłów birżańskich $w$ XVII wieku, „Papirowe materie” Piotra Kochlewskiego. O działalności pisarskiej sekretarza Radziwiłłów birżańskich w pierwszej połowie XVII wieku, Przy pogrzebach rzeczy i rytmy. Funeralia Radziwiłłowskie z XVII wieku. Członek Komisji Lituanistycznej przy Komitecie Nauk Historycznych PAN w Warszawie. E-mail: mariolajarczyk22@gmail.com 